\title{
O grande ressonador: o que a antropologia histórica e uma abordagem etnográfica da sala de teatro podem nos dizer sobre o público ${ }^{1}$
}

\author{
Marie-Madeleine Mervant-Roux² \\ (Traduzido por Camila Scudeler ${ }^{3}$ )
}

O espectador é "o principal parceiro do ator", como disseram, Max Reinhardt e, mais recentemente, Peter Brook? Será que o espectador é realmente o "quarto criador" da peça de teatro (junto com o autor, o encenador e o ator), como sugerido por Meyerhold? Ou o "terceiro companheiro" (depois do autor e o ator), como Jean Vilar costumava dizer? Ou "um protagonista, o protagonista", para usar a fórmula de Giorgio Strehler? Podem estes termos ser entendidos literalmente? Será que a plateia tem o poder de intervir concretamente no processo da apresentação? Isto pode ser verificado? Podemos descrevê-lo? Podemos medi-lo? Estas foram as perguntas para as quais eu esperava encontrar respostas quando fui nomeada para um cargo de pesquisa no $\mathrm{CNRS}^{4}$ em 1986.

1 Artigo original: "The great resonator. What historical anthropology and an ethnographic approach to the auditorium can tell us about audiences", translation by Ghislain Casas and Gay McAuley, in About Performance, n¹0, 2010, Audiencing: The Work of the Spectator in Live Performance, co-ed. Laura Ginters and Gay McAulay, University of Sydney, Department of Performance Studies, 2010, p. 223-240. About Performance pode ser acessada em: http:// sydney.edu.au/arts/performance/research/publications.shtml

N.T.: optou-se por traduzir audience às vezes como plateia, às vezes como público - quando se trata dos espectadores na sala, plateia, mas quando se refere aos espectadores muito tempo depois da representação, público; performance como apresentação (no sentido da apresentação de uma obra teatral) e auditorium como auditório (no sentido do espaço ocupado pelos espectadores no espaço teatral)

2 Marie-Madeleine Mervant-Roux é diretora de pesquisa do ARIAS (laboratório de pesquisa sobre a intermidialidade e as artes do espetáculo) do CNRS (Centro Nacional de Pesquisa Científica, França). Seus trabalhos sobre o espectador e sobre os teatros dos amadores se inscrevem em uma pesquisa sobre a função dramática na Europa. Ela coordena desde 2008, em parceria com Jean-Marc Larrue do CRlalt (Centro de Pesquisas Intermidiais em artes, letras e técnicas) de Montreal, um projeto internacional sobre "O som do teatro (séculos XIX-XXI)", cujos primeiros trabalhos foram apresentados nos números 197, 199 e 201 da revista francesa Théâtre/Public: Leson du théâtre : Le passé audible (2010-3); Dire l'acoustique (2011-1) et Voix Words, words, words (juilletseptembre 2011). Para maiores informações, consultar o site: www.arias.cnrs.fr

3 Atriz e professora. Mestre em Artes Cênicas na área de Pedagogia Teatral pela ECA/USP". Pesquisadora do CEPECA - Centro de Pesquisa em Experimentação Cênica do Ator- ECA/USP.

4 N.T.: Centre National de la Recherche Scientifique, França. 
A hipótese que estou propondo aqui, em revisitar uma metáfora usada por muitos encenadores e atores no início do século XX, é a da plateia como ressonador ou caixa de som. Isso dota o espectador de uma função ainda mais vital do que as sugeridas pelos profissionais de teatro citados acima, enquanto ao mesmo tempo levanta questões sobre a ênfase no momento de co-presença que constitui a apresentação teatral. De acordo com minha hipótese, o público de uma produção teatral - isto é, todas as pessoas que participaram das apresentações sucessivas do espetáculo - age como um grande "ressonador" da apresentação, durante, imediatamente após e muito depois das apresentações. Minha proposta é baseada em três fases bem diferentes de pesquisa e reflexão.

Na primeira fase (1986-1998), tentei responder às questões levantadas montando uma metodologia inspirada na etnografia e no trabalho de campo feito nos teatros de Paris, que consistam no seguinte: observações de uma série de apresentações de uma mesma peça (fazendo anotações logo após deixar o teatro); gravações de som feitas dentro do auditório; um grande número de entrevistas com os espectadores e um número ainda maior de questionários (escritos à mão, distribuídos no início da apresentação ou entregues durante o intervalo a voluntários, que tinham duas semanas para devolvê-los para mim). A seleção dos espetáculos foi deliberadamente restrita àqueles realizados em teatros "tradicionais", com palco elizabetano/ferradura (como o grande auditório no Théâtre des Amandiers de Nanterre) ou palco italiano (como o Théâtre de l'Athénée) com a plateia sentada, imóvel e virtualmente em silêncio. Os espetáculos eram - também por uma escolha deliberada - extremamente variados em termos de estilo, como se pode ver a partir dos seguintes exemplos: Elvire Jouvet-40 (Brigitte Jaques, Théâtre de l'Athénée, 1986), Le Jeu de Faust (Théâtre du Radeau, e vários outros locais, 1988-1989), Hamlet (Patrice Chéreau, Avignon, Nanterre, MKHAT Moscou, La grande Halle, em La Villette, 1988-1989), Je ne reviendrai jamais (Tadeusz Kantor, Pompidou Centre, Théâtre de Chaillot, 1988-1989), Iphigénie à Aulis (Théâtre du Soleil, 1990-1991).

A segunda fase (1998-2006) foi caracterizada por um distanciamento duplo, tanto crítico quanto reflexivo, em relação ao objeto da minha pesquisa. A distância crítica foi causada pelo fato de que eu tinha começado outros dois projetos, um sobre teatro amador e outro sobre o trabalho do diretor Claude Régy (MERVANT-ROUX, 2004 e 2008), e, como resultado deste trabalho, a questão do espectador, longe de 
ser apagada ou esquecida, agora me apareceu sob uma nova luz. A distância reflexiva foi provocada pela minha percepção de que a primeira fase de minha pesquisa tinha involuntariamente contribuído para uma redefinição do público como um "co-ator", uma afirmação que eu considero, na verdade, muito questionável. Decidi, portanto, examinar como os historiadores do teatro tinham lidado com o problema do público, e assim começou-se a constituir um inventário de figuras "autóctones" do espectador, ou seja, figurações construídas dentro do campo fechado da teoria teatral, de 1950 até hoje. Como resultado desta investigação descobri que a questão tinha sutilmente evoluído e então me voltei para a antropologia histórica para tentar pensar sobre isso novamente (MERVANT-ROUX, 2006).

A terceira fase começou em 2008 e envolve a volta para os auditórios armada com um gravador digital, para realizar um programa de gravações auditivas de uma nova série de apresentações. Este trabalho de campo ocorreu em um quadro teórico que é bastante diferente do primeiro, mas nasceu diretamente dele. Minha pesquisa atual refere-se ao "o som do teatro" e o modo como a plateia ouve. As gravações puramente auditivas, realizadas sistematicamente desde o início até o final da peça, com foco no evento teatral inteiro, incluindo as plateias, nos permitem considerar a apresentação como um organismo vivo que evolui ao longo de um período de tempo. Esta pesquisa sobre o fenômeno do som, aplicado a outros objetos, está abrindo novas perspectivas sobre a função do espectador na prática da performance contemporânea.

\section{De volta à primeira fase da pesquisa: a plateia como caixa de ressonância}

A primeira fase da pesquisa permitiu dar respostas positivas aos meus interlocutores no CNRS: sim, a plateia intervém concreta e permanentemente no que constitui, a cada dia, a criação definitiva da obra de teatro. Podemos chamar o espectador de parceiro. De tempos em tempos - esses momentos são inesquecíveis - o espectador até se torna um "co-criador". Minha apresentação nesta revista dos resultados desta pesquisa tomará a forma de um diálogo com as declarações feitas por Gay McAuley (1999), em particular no capítulo 7 ("o espectador no espaço"); seu livro foi publicado aproximadamente ao mesmo tempo em que o livro resultante de meu trabalho de campo (MERVANT-ROUX, 1998). Há um consenso considerável entre nós, mas também vou assinalar algumas divergências ${ }^{5}$.

5 N.A: A professora Gay MacAuley organizou o número da revista About Performance onde este artigo foi originalmente publicado, o que explica meu diálogo com suas propostas. 
Um dos resultados importantes do meu trabalho de campo diz respeito à organização interna do espaço reservado para a plateia, significativamente referido em francês por uma metonímia, "la salle", que engloba os significados de contêiner, bem como aquilo que está contido: a plateia e o auditório. Baseando-me em experiências pessoais e entrevistas com espectadores, cobrindo cerca de dez produções e/ou salas de apresentação, dei atenção especial à localização física do espectador em relação ao palco. Posições foram definidas seguindo dois critérios: distância e ângulo de visão. Como alega McAuley, cada posição é diferente, mas essas diferenças não são, como ela sugere (1999, p.245), redutíveis simplesmente a uma melhor ou pior qualidade de percepção. A abordagem pelo método misto que adotei revelou a geografia oculta do auditório: há três zonas proxêmicas, que determinam o mesmo número de posições básicas do espectador, cujas características eu descrevi. A delimitação precisa destas zonas está ligada, principalmente, à percepção recíproca do rosto e da possibilidade ou impossibilidade de contato visual entre o ator e o espectador. Dependendo do espetáculo ou da apresentação, estas zonas são mais ou menos "ativadas" (como pode ser dito das zonas cerebrais). É apropriado, portanto, falar de um espectro de nuances perceptível correspondente a diferentes áreas de cada local.

O olhar desempenha um papel importante e multiforme no teatro (ver "o complexo jogo de olhares" MCAULEY, 1999, p.255-256) e torna-se ainda mais poderoso quando dirigido da plateia para o palco. A parte essencial desta interação recíproca não é, no entanto, tão dependente de fatores visuais como é do canal auditivo, tal como mostrei em outros estudos dedicados à dimensão acústica da apresentação. Em contraste com o ator, o espectador não têm que atuar, mas suas emoções e suas mentes desempenham um papel, manifestado quando há o transbordamento dramático durante a apresentação, seja pelo riso, silêncio súbito, agitação, etc. A manifestação deste extravasamento é audível ao invés de visível, o que ecoa as ideias de Gay McAuley (1999, p. 245) em relação a energia e sua declaração: "o que está aqui em pauta é muito mais sutil do que aprovação / reprovação" (MCAULEY, 1999, p.247).

A imagem do ressonador ${ }^{6}$ pareceu-me a melhor expressão desse fenômeno, a ideia de "ressonância" cria um link entre a emoção e o som dos espectadores (o meio pelo qual suas experiências tornam-se perceptíveis para os pesquisadores). Gravações feitas

6 N.E.: O ressonador é um dispositivo que exibe ressonância ou comportamento ressonante e é utilizado para ressonar em uma frequência em particular, modulando as ondas, sejam sonoras, de rádio, etc. Desta forma algumas ondas são amplificadas enquanto outras podem ser ignoradas. 
dentro do auditório durante as apresentações me permitiram explorar cuidadosamente a forma como a plateia modula a apresentação. Isto ocorre de forma tripla envolvendo o ritmo, o tom e a intensidade dramática da cena. Os arquivos sonoros revelam a singularidade absoluta de cada performance - um fenômeno essencial que não é percebido a menos que se assista a várias apresentações de um mesmo espetáculo. Como apontado por McAuley (1999, p.247), os atores são conscientes disso, mas raramente falam de suas experiências. Esses estudos me permitiram observar a formação, em cada apresentação, de uma comunidade efêmera (MCAULEY, 1999, p.250), cujos aplausos constituem uma espécie de rápido autorretrato auditivo. Os aplausos podem ser vistos como o único momento codificado de expressão direta da plateia, e essas gravações permitiram-me apreciar as variações quase infinitas de um esquema rítmico, dos quais os elementos básicos são bem conhecidos (bravos, chamadas para retornar ao palco7, etc.), mas que têm uma forma diferente em cada apresentação e para cada nova plateia.

Este trabalho confirmou que a atividade do espectador é um elemento estrutural na gênese de um trabalho teatral. Intervindo na forma da apresentação (no momento e local específicos do evento), a plateia contribui para moldar o seu significado emergente. A plateia não articula um significado específico, mas especifica um significado desarticulado (o escopo deste artigo não me permite entrar em mais detaIhes sobre as condições envolvidas neste processo).

Este estudo forneceu um lembrete de que interações decisivas entre o palco e os espectadores, muitas vezes associadas a formas populares antigas e de teatro de feira ou com usos contemporâneos de transgressões físicas, na verdade sempre acompanharam apresentações clássicas, às vezes com violência considerável (silêncio absoluto, gritos, tumulto, divisão da plateia em facções opostas), o que constitui outro ponto de acordo com Gay McAuley (1999, p.239-245). Espaços teatrais organizados de forma tradicional não impedem a plateia de desenvolver uma atividade intensa, cuja grande parte certamente passa despercebida. É justamente porque essa atividade frequentemente não é percebida conscientemente que é tão eficaz. Poderíamos emprestar a expressão, "a inatividade animada”, de Daniel Stern para descrever de

\footnotetext{
7 N.E.: Na França há o costume do agradecimento ser feito com pelo menos 3 retornos ao palco por parte dos atores. Os espectadores chamam os atores de volta para o palco a cada vez que eles saem. Para dizer que gostaram de uma peça os espectadores podem continuar chamando inúmeras vezes os atores para o palco até se darem por satisfeitos.

8 Daniel Stern é um psicólogo especializado nos primeiros meses de vida. Seus filmes mostrando o dia de mãe e filho influenciaram os trabalhos de Bob Wilson em relação a cortes e câmera lenta.
} 
forma muito eficaz esta atividade. A inatividade animada dos espectadores transforma o momento da apresentação em um evento social real, que por sua vez implica certa distância estrutural da ação no palco (MCAULEY, 1999, p.274-277).

\section{Consequências problemáticas da metáfora}

Boa parte das pesquisas publicadas entre os anos de 1980 e 1990, que lidavam com a atividade da plateia a descrevia em termos dramáticos. Estudiosos saltavam muito rapidamente da observação de que a plateia desempenha "um papel" na apresentação, para uma crença na natureza teatral desse papel. Pouco a pouco, os espectadores passaram a ser vistos como verdadeiros parceiros, cuja principal função era direta e a participação quase artística na ação do palco. O desenvolvimento natural foi que eles passaram a ser vistos por sua vez, como artistas. O espectador torna-se "um ator em potencial", apenas esperando o momento dele mesmo saltar para o palco (GUÉNOUN, 1997, p.165-166).

Minha rejeição intuitiva dessa concepção do espectador foi baseada em minha própria experiência de ida ao teatro, bem como em declarações de inúmeros diretores cujo trabalho tem sido associado com a promoção da tal "participação direta" da plateia, mas que de fato negaram que isto estava acontecendo ou mesmo que era desejável.

Entre os diretores, cujo trabalho eu observei, poderia citar Ariane Mnouchkine que disse: "Embora eu não concorde com todas as ideias de Grotowski, eu, assim como ele, acho que a plateia não deve modificar a apresentação" (MNOUCHKINE, 1976, p.15) e Tadeusz Kantor: "Quando apresentamos A Classe Morta em Roma, em 1978, os espectadores gritaram para nós 'O que podemos fazer?' Eu respondi 'não façam nada"' (KANTOR, 1989, p.15). Ao mesmo tempo, a pesquisa que eu estava realizando, em projetos conjuntos e sozinha, sobre produções que tinham sido criadas há tempo suficiente para não estarem mais na memória pública (por exemplo, as produções de Claude Régy entre os anos de 1950 e 1970) e a forma como estas produções viveram na memória de alguns espectadores por muitos anos, até mesmo décadas, me deram pistas para a reflexão. Enquanto a dimensão participativa do teatro não deve ser negligenciada - e, de fato, tinha sido negligenciada demais - sugiro que ela não constitui o elemento decisivo da apresentação. Além disso, o momento da apresentação, ao mesmo tempo em que tem um papel importante na vida do teatro, não constitui em si mesmo toda essa vida. O paradigma teórico do "diálogo" entre palco e plateia -rapida- 
mente abandonado em sua forma semiótica, mas mantido em termos de noções de interatividade e reatividade- teve como consequência o fato dos teóricos se interessarem pelo evento teatral, no momento em que acontece, e se esqueceram o que se passa depois. Foi dada prioridade à imediaticidade, ao corpo expressivo, ao invés da atividade mental e da lembrança, e da suspensão da reação.

Tudo isso só serviu para confirmar um fato bem conhecido da história do teatro: os espetáculos que trabalham desfrutando o sucesso popular óbvio e imediato não são necessariamente aqueles que deixam marcas duradouras. Como este novo conceito de espectador, fisicamente ativo no momento da apresentação, se desenvolveu a tal ponto que ameaçou submergir o outro conceito, o de "visitante da noite"? (REGNAULT, 1986). Como isso aconteceu? É possível refazer as fases deste processo?

\section{A segunda fase da pesquisa: mitologias do espectador (1950-2000)}

"Longamente ignorado ou visto como uma quantidade insignificante, o espectador é agora o objeto favorito de estudos em semiologia ou estética da recepção." É assim que Patrice Pavis começa o verbete de "Espectador" na edição revisada de 1996 de seu Dictionnaire du Théâtre. Na primeira edição (1980), não havia tal verbete. Qualquer leitor que o procurava era redirecionado para o verbete "Recepção".

Os primeiros estudos dedicados exclusivamente à questão da plateia são de cerca de somente 50 anos atrás. Estes incluem artigos como o pioneiro "Du public" de Léon Chancerel (1944), "Définition du public" de Jean Vilar (1946), e a monografia de Jean Doat, Entrée du public: la psychologie collective et le théâtre (1947). Em todos esses trabalhos, o tipo de grupo que é construído pelos espectadores é claramente distinguido da "massa". Estudos históricos e sociológicos especificamente dedicados ao tema foram desenvolvidos mais tarde: Le public de théâtre et son histoire de Maurice Descotes foi publicado em 1964. O "espectador" é uma noção que raramente aparece na década de 1950 (o artigo de David Victoroff foi publicado em 1955), mas veio à tona duas décadas depois, em vários campos de pesquisa: na psicanálise (Octave Mannoni Clefs pour l'imaginaire ou l'autre scène em 1969); na semiótica (Anne Ubersfeld L'école du spectateur em 1981); em estudos de recepção (muitos artigos de Patrice Pavis na década de 1980).

A fim de traçar a história recente da noção de espectador, escolhi o método de "detalhamento". Primeira amostra essencial: uma pesquisa de publicações de 
conferências acadêmicas dedicadas ao tema na França entre 1984 e 2005. Segunda amostra essencial: análise das conferências de abertura promovidas pelos organizadores do Festival de Avignon ${ }^{9}$ e publicadas anualmente desde 1947 no programa do festival. Resumindo os resultados dessas pesquisas, podemos distinguir três fases na evolução do conceito.

Década de 1980. De membro da plateia a "aquele que está a olhar"

Estudos do público, que pertenciam à sociologia cultural tradicional, revitalizada na altura pela obra de Pierre Bourdieu, foram abandonados e substituídos por análises da ação de percepção durante o espetáculo. Como Anne-Marie Gourdon (1982), entre outros, apontou, questionários não nos permitem entender o que a plateia está fazendo durante a apresentação e até mesmo os critérios utilizados para analisar as respostas passam a ser problemáticos. Durante algum tempo pensou-se que uma resposta pode ser encontrada na abordagem psico-fisiológica, e naquele momento os próprios profissionais de teatro foram por este caminho. Denis Bablet disse: "cada diretor de teatro - como Eisenstein entendeu muito bem - dirige o espectador" (BABLET, 1984). Neste momento, a "percepção criativa do espectador" foi concebida a partir do enquadramento artístico (o espaço do teatro), e em termos artísticos (uma vez que a plateia deveria ser submetida à sua própria mise en scène). Os críticos também falaram da "arte do espectador".

\section{Década de 1990. Do espectador ao espectador}

O espectador [...] é antes de tudo uma potencialidade, uma virtualidade um puro devir. É por isso que a questão do espectador não deve se restringir aos problemas de recepção ou a fatores exclusivamente semióticos ou sociológicos, mas deve, antes, ser aberto à sua dimensão profundamente simbólica (ou seja, criativa), e, simultaneamente, ao seu caráter de teste de realidade. (RIPOLL, 1996, p.5)

A abordagem política tornou-se psicanalítica: a plateia teve que "impor o silêncio sobre si mesma, a fim de ouvir outras línguas" (BLANC, 1996, p.35). A função mais importante do teatro passou a ser vista como de promotora de um aprofundamento da vida imaginária do público. A posição de espectador tornou-se paradigma de certa distância, ao mesmo tempo crítica e criativa, tão preciosa e ameaçada em uma socie-

9 O festival de Avignon (realizado na cidade de Avignon, sul da França) é realizado anualmente no mês de julho e é atualmente um dos mais importantes festivais de teatro da Europa, como foco especial para a cena contemporânea europeia. 
dade midiatizada. Fomos lembrados de que "aquele que assiste" está participando da fundação mais antiga do teatro. O observador encarnou a resistência ao espetacular, e foi elevado ao status de modelo.

\section{O início do século 21. Teatro como "comunidade"}

As noções dominantes de "assembleia" e "comunidade" - que, insisto, pertencem mais ao campo do ritual do que da apresentação dramática - apagam ou borram a distinção entre palco e plateia. O teatro foi, por vezes, no passado, experimentado e pensado como um espaço utópico do trabalho e da vida coletiva, mas os atores desses projetos anteriores não assumiram o envolvimento dos espectadores em sua ação, nem definiram a sociedade como um todo em relação à sua atividade. Isto é, no entanto, o que começa a ocorrer agora. Se fosse para esboçar uma imagem do universo emergente da concepção de teatro deste período, seria um cosmos Copérnico, no centro do qual estaria o próprio palco (significativamente, o termo técnico "plataforma" entra no lugar da palavra "palco"). A representação de tempo coincide com a de espaço: obras teatrais já não são vistas como parte da história social, mas quase o oposto. A memória e a imaginação da plateia são evocadas apenas porque melhoram o "modo temporal do ser" que o teatro deveria ter se tornado.

Nesse contexto, marcado por valores neo-ritualísticos de comunhão ou de operação coletiva, vimos o retorno da velha ideia - recorrente desde os anos 1960 que iguala imobilidade física à passividade. Várias soluções são sugeridas:

- dotar o espectador da função de crítico. Na década de 1980, Jean Jourdheuil desdenhou daqueles que ele descreveu, ironicamente, como "espectadores profissionais" (JOURDHEUIL, 1984, p.39). Duas décadas depois, esses "espectadores profissionais" estão em toda parte e ganharam reconhecimento oficial. Um sistema de produção artística passou a ser aquele no qual a produção pode encontrar um modo de existência, sem nunca cruzar o caminho de qualquer pessoa fora do "espaço argumentador do mundo da arte." 10

\footnotetext{
10 Emprestei esta expressão de Jean-Marie Schaeffer: "Exceto quando exercemos a profissão de crítico (e mesmo assim), não nos envolvemos numa atitude estética a fim de expressar um juízo de gosto, mas simplesmente porque esperamos que seja uma experiência satisfatória. O julgamento que seremos eventualmente levados a formular é apenas uma conseqüência daquela experiência. A fim de percebê-lo, devemos deixar de reduzir atitudes estéticas relevantes à atitudes das pessoas que, por muitas razões, consideram as obras do ponto de vista de sua posição no espaço argumentador do mundo da arte" (SCHAEFFER, 2000, p.53).
} 
- deslocar o espectador fazendo-o mover-se, atuar, comunicar-se, agir (mas sem a dimensão política fundamental para o trabalho de Augusto Boal).

- substituir a condição do espectador por outras condições. "A própria palavra "espectador" já não é necessariamente apropriada - testemunha, visitante, cliente, ator, público, comunidade, tribo, observador" (Mouvement, 2005).

Em suma, a atividade da plateia durante a apresentação foi descrita pela primeira vez por si mesmo, como uma "experiência" estética ou relacional que, foi sugerido, possuía mais poder do que a experiência real, devido ao seu ser concentrado através de uma estrutura formal e duração limitada. Em seguida, o elemento essencial passou a ser o evento ao vivo, e a plateia, podia ser considerada boa, se ela colaborasse criação deste sucesso. ${ }^{11}$ No auge de seu enobrecimento, a figura do espectador, que tinha se tornado um verdadeiro "espect-ator", foi paradoxalmente esvaziada: por ser tão completamente integrada no teatro, perdeu a sua realidade externa de espectador. O último passo dessa progressão tem sido o surgimento de candidatos alternativos: 0 mais dinâmico e mais midiatizado deles é certamente o "interator".

A forma como o "hemisfério escuro" (Max Reinhardt) foi retomada por estudiosos em estudos de teatro desde os anos 1950 e o crescente interesse que esta noção tem despertado parece, paradoxalmente, ter exacerbado uma espécie de cerco auto-reflexivo e, como conseqüência, uma atenuação das relações entre a disciplina e o mundo externo. Este fenômeno não se aplica somente aos estudiosos franceses. $\mathrm{O}$ "evento teatral" inglês é pensado como um processo que ocorre "entre artista e espectador", enquanto as coisas exteriores ao teatro são consideradas apenas como o "contexto" do evento (SAUTER, 2000). O resultado é um teatro, mais precisamente uma imagem de um teatro, que não é desprovida de nuances em termos do momento de interação, espetáculo físico ou apresentação estética, mas a partir da qual a dimensão essencial até agora, isso é o funcionamento do que tem sido chamada "função dramática", é cada vez mais ausente, não é reconhecida ou simplesmente não é discutida.

\section{Repensando a questão através da antropologia histórica: o espectador como guardião da realidade}

A expressão "guardião da realidade" é usada pelo historiador teatral Élie Konigson, especialista em teatro medieval e renascentista, para designar a função social

11 Este esquema foi confirmado pelo estudo de editoriais do Festival de Avignon. 
do espectador nas primeiras formas de performance teatral que foram organizadas nos centros das cidades da Europa pré-industrial. $O$ termo refere-se ao que ele chama de "função dramática", uma função simbólica que ele vê como um complemento para as funções econômicas e políticas. $\mathrm{O}$ ator, diz ele, é o representante da comunidade "em relação às zonas intermediárias do espaço de jogo" e o "off-stage irreconhecível." O espectador, que assiste ao ator e "vislumbra os mundos impossíveis que são construídos e narrados por seu representante no palco" (KONIGSON, 1994, p.46-47) torna-se um "mediador" entre o teatro e a cidade, que ele encarna à frente do palco.

A função dramática, que irá revelar-se um elemento fundamental na constituição da sociedade ocidental moderna, requer para o seu funcionamento eficaz não apenas atores, ficções representadas e transeuntes reunidos para assistir. $O$ dispositivo que vem a definir-se é muito mais sutil na organização dos papéis. Enquanto os atores têm de assumir a sua função de explorar o desconhecido, os espectadores também devem ser intermediários: devem ser sensíveis aos mundos imaginários criados no palco, mas nunca devem deixar de "representar" a realidade à qual pertencem. A missão do espectador de encarnar a cidade no espaço teatral é o que Elie Konigson, no artigo citado, descreve por meio da metáfora de "guardião da realidade." Esta metáfora, com a sua mistura de elementos prosaicos (a primeira palavra evoca a figura de um vigia de plantão) e abstração filosófica (horas de trabalho teórico seriam necessárias para esclarecer o significado do termo "realidade"), confirma que o espectador pertence a um mundo fora do teatro. O sentido principal da palavra "realidade", e é a essa definição que irei me ater aqui, é "aquilo que existe independentemente do sujeito, o ambiente material e social do homem."12

O espectador / guardião não "protege" a cidade contra a ficção, mas a "guarda" diante da ficção, constantemente confrontando uma à outra: assim como o ator é o "mensageiro" da cidade para os mundos invisíveis, assim também o espectador é um intermediário. Ele é, à sua maneira, um poeta. Elie Konigson descreve-o como uma figura "mediúnica":

O papel propriamente xamânico do espectador, este representante da cidade colocado em frente aos mundos impossíveis da cena, também é expressa por este corpo de aparência sonolenta, imóvel, presença pesada do espaço urbano atrás do teatro, atento às sombras que se movem na cena. (KONIGSON, 1993, p.189)

12 Artigo "Réel", TLF (Trésor de la Langue Française). Paris: CNRS, Institut National de la Langue Française. 
O fato de que o espectador pode "seguir" os atores em suas ficções não deve ser visto em nível individual, mas em nível coletivo. É aqui que a riqueza da metáfora xamânica é revelada, pois nesta ação o espectador tem um papel fundamental dentro da comunidade: ao estar em contato com o invisível e seus possíveis perigos, ele torna-se dotado de eficácia terapêutica. É através dele, e por ele tão somente, que o teatro será capaz de produzir efeitos em curto prazo e, mais importante, em longo prazo, muito tempo depois de os atores terem deixado a cidade.

Na perspectiva antropológica adotada aqui, o teatro é um sistema de representações complementares. A palavra "espectador" abrange apenas uma parte da função de quem tem duplo papel neste sistema. Sua ação vai da cidade para o palco, porque ele encarna, em face do ator, "a verdade dos tempos e dos espaços conhecidos", mas também na direção oposta, do palco para a cidade: "Um certo tempo, metade fabuloso metade familiar, transforma o espectador, por sua vez, em um mediador" (KONIGSON, 1994, p.47). Podemos, assim, definir o teatro como a associação de dois grandes mediadores, um no palco, outro no auditório, colaborando juntos em uma atividade mítica que transcende cada um deles. O espectador, em particular, não flutua entre dois mundos. Ele só pode ser um "médium" eficaz precisamente porque ele é, por um lado, firmemente ancorado na realidade social, e por outro lado, capaz de perceber a poesia do palco. Isto o deixa mais próximo do feiticeiro do que do mediador cultural.

Os desenvolvimentos recentes na teoria do teatro, descritos acima, em que o público arrisca perder sua função de mediador, tomaram lugar imperceptivelmente. Os resultados são, no entanto, claramente observáveis na estetização da imagem do espectador: na imagem dominante que está sendo promovida do espectador, a estreita ligação entre o espectador e a cidade (isto é, a sociedade vista como espaço de ação política) foi substituída por uma relação quase orgânica com o teatro e com a comunidade artística em geral. Isso tende a obscurecer o fato de que os espectadores são fundamentalmente habitantes de longo prazo da cidade, em comparação aos atores que são essencialmente itinerantes. Mesmo quando os atores são residentes estáveis, como tende a ser o caso hoje em dia, sua função simbólica é trabalhar nas fronteiras de códigos sociais normativos. Como resultado de toda essa evolução, o teatro é incapaz de exercer a "função dramática", independentemente do assunto escolhido ou das reivindicações que são feitas. Este fenômeno é evidente (em) e exacerbado 
pela "festivalização". Estou usando o termo literalmente (há um número crescente de festivais) e figurativamente (locais de teatro permanentemente se "festivilizam"):

Costumava-se falar da Europa como um lugar de cultura, a Europa agora é um lugar de festivais. Cultura tornou-se pura aparência. E este é, talvez, porquê em termos culturais a Europa de hoje dá um tom tão oco. (JOURDHEUIL, 2009, p.56)

\section{A terceira fase da minha pesquisa: duas novas manifestações do grande ressonador}

Os primeiros resultados da minha pesquisa sobre "o som do teatro," na realidade o som da plateia ${ }^{13}$, confirmam a importância do que pode ser chamado de "pontuação" da encenação por plateias sucessivas. A pontuação é poderosa e imprevisível e isso implica que existem exceções à homogeneização geral tanto das apresentações como das plateias. Esta mesma pesquisa coletiva sobre a dimensão sonora do teatro levou a um interesse em novas formas de mídia mista que se baseiam em performance, instalação e paisagens sonoras, pois me parece que é para estas formas que a função dramática migra e está a reconstituir-se. É nelas que ela pode ser experimentada como uma realidade coletiva. Esta é, de qualquer modo, a hipótese que agora apresento, antes de resumir as minhas observações mais recentes sobre as formas em que a memória do público está sendo estruturada pelas práticas dos novos espectadores (MERVANT-ROUX, 2010a, 2010b).

\section{Arte sonora e os novos espaços "dramatizados/dramatizáveis"}

Uma série de performances coreográficas e visuais recentes, acompanhadas por composições sonoras originais, improvisadas ao vivo e em plena vista dos espectadores por músicos / engenheiros / técnicos de palco co-criadores do espetáculo parecem exigir dos espectadores um tipo teatral de resposta, isto é, aquela que é ao mesmo tempo pessoal e coletivamente dramatizada, mesmo que não haja nestas performances nenhuma ação dramática no sentido habitual do termo. Entre vários exemplos, o mais típico e o mais conhecido é Paso Doble. ${ }^{14} \mathrm{~A}$ minha hipótese é que a atenção particular dos espectadores, mantida durante um período considerável

\footnotetext{
13 Um de meus estudos recentes diz respeito à produção de Ubu criado por Jean-Pierre Vincent na Salle Richelieu na Comédie-Française em 2009.

14 Produção criada por Josef Nadj, coreógrafo, e Miquel Barceló, pintor e escultor. A paisagem sonora foi criada por Alain Mahé, saxofonista, compositor e performer de música eletro acústica (Festival d'Avignon, 2006).
} 
(a obra de Nadj e Barceló dura uma hora) e expressa de diversas formas durante e após as apresentações (silêncio arrebatador nas apresentações de Avignon, riso e respostas físicas espontâneas da plateia muito animada que incluía um grande número de crianças no Théâtre des Bouffes du Nord, em Paris), pode ser atribuída à ruptura das relações teatrais normais entre o que é visto e o que é ouvido. Seguindo o método Intermédiale, que elaborei, pareceu-me que estas apresentações adquiriram força por sua articulação "fresca" - por "fresca" queremos dizer tanto "nova" quanto também "abrupta" - de duas artes e, ainda mais, de duas mídias, distintas: ${ }^{15}$ a antiga mídia que é o teatro e a mídia contemporânea que é a "arte sonora" (a écriture sonore de Deshays) ${ }^{16}$. A arte sonora, mais próxima das artes plásticas do que da música, tem emergido na França durante a última década, não só através de uma série de obras criativas, como também pelo início de uma abordagem teórica e pedagógica demonstrada por ações como a de Daniel Deshays que resultou na criação de um curso especializado na École nationale supérieure des beaux-arts de Paris (França).

Nas performances que observamos, o performer, parecia, no início, um "gravador de som" que mantinha sua autonomia em relação ao resto da performance. Ele não desempenhava um papel dentro da mise en scène, como artistas de som têm feito, por vezes, de forma brilhante, em produções teatrais desde os anos de 1950. Em alguns casos, não havia encenador. Paso Doble, por exemplo, foi criado por um coreógrafo/ bailarino e um pintor/escultor. Muitas vezes o "engenheiro de som" trouxe práticas acústicas e auditivas que eram estranhas ao teatro. Em algumas ocasiões, ele começava a ouvir o que os artistas estavam fazendo, gravando seus sons, em seguida, retrabalhando e colocando-os novamente para tocar. Todo esse trabalho era visível para os espectadores em Paso Doble. A composição semi-improvisada por Alain Mahé lidava com a própria temporalidade e constituía uma espécie de análise em curso do que estava sendo visto:

Os sons são gerados [...] quase que instantaneamente, mas não completamente. E o breve intervalo entre o som ao vivo e sua reprodução é o momento de um olhar ou de uma escuta que representa um momento de desapego, uma desconexão do turbilhão de imediatismo, uma ruptura da sincronicidade. (DESHAYS, 2006, p.70)

15 Mídias: "Estruturas de comunicação realizadas socialmente. O termo 'estrutura' implica ao mesmo tempo as tecnologias e os protocolos de uso associados a eles; e 'comunicação' implica uma prática cultural baseada em uma co-locação ritualizada no mesmo espaço mental de indivíduos compartilhando e participando de ontologias populares de representação" (GITELMAN, 2006, p.7).

16 "Escritura do sonoro" (Ecriture sonore) é o termo proposto por Daniel Deshays (2006). Outros termos usados incluem "composição sonora", "design de som" e "paisagem sonora". 
Isso pode explicar como a atenção dos espectadores tem sido tão intensamente cativada e como suas mentes ficaram permanentemente alerta. ${ }^{17}$

A sugestão feita foi de que o "enxerto" de duas mídias (aqui, teatro e arte sonora), juntamente com as rupturas que isso implica, poderia ser por si só um meio de revitalização do evento teatral. Esta sugestão pode parecer apoiar a noção de "dissenso" proposta por Jacques Rancière, e elevar as performances, descritas, ao status de modelos no campo da "política da estética", como definido em Le spectateur émancipé18: "as formas da experiência estética e os modos da ficção criam assim uma paisagem inédita do visível, formas novas de individualidades e conexões, ritmos diferentes de apreensão do que é dado, escalas novas." A partir desta nova paisagem, ele continua: "dos modos do isso e do eu" podem surgir posteriormente "os mundos próprios do nós político." (RANCIÈRE, 2008, p.65)

Mas as coisas não são assim tão simples, porque Rancière postula a existência de dois tipos, ou dois níveis de "dissenso". O primeiro nível, produzido pela ficção, ${ }^{19}$ parece-me ser essencial para a existência da peça teatral; o segundo nível, que em nome da emancipação e reconfiguração permanente se opõe a qualquer distribuição estável de papéis e situações, ${ }^{20}$ é, em minha opinião, fundamentalmente oposto à própria constituição do espaço teatral.

Se as novas cenas interartísticas, acima descritas, podem ser vistas como a localização de um teatro revivificado, inspirado e inspirador, portanto, uma forma de prática artística inscrita na política ${ }^{21}$, não é (como Jacques Rancière sugeriu e como outros assumiram) porque essas formas se libertaram do esquema genérico do dispositivo teatral, sua estrutura espacial e suas funções ${ }^{22}$, mas porque os elementos-chave

17 O site Tadorne, um blog francês de espectadores engajados, entre outros, publicou duas críticas sobre a performance que podem ser acessadas em: http://www.festivalier.net

18 Em português (Brasil)- RANCIÈRE, Jacques. O espectador emancipado. São Paulo: WMF-Martins Fontes, 2012. 19 "Ficção [...] é o trabalho que realiza dissensos, que muda os modos de apresentação sensível e as formas de enunciação, mudando quadros, escalas ou ritmos, construindo relações novas entre a aparência e a realidade, o singular e o comum, o visível e sua significação" (RANCIÈRE, 2012, p.64)

20 "Essa lógica dos corpos tem seu lugar numa distribuição do comum e do privado, que é também uma distribuição do visível e invisível, da palavra e do ruído, é o que eu propus designar com o termo polícia" (RANCIÈRE, 2012, p.60).

21 No sentido que Claude Lefort dá esta palavra em seu Essais sur le politique: "É só no controle da evidência de novos desenvolvimentos, em continuamente perguntar o que está acontecendo em relação à formação e evolução da democracia contemporânea [...] que temos alguma chance de avaliar a política [...]" (LEFORT, 1986, 12).

22 Estamos falando aqui, vamos lembrar, somente do teatro ocidental e, mais precisamente, da prática teatral europeia 
deste esquema tradicional estão todos presentes. A heterogeneidade e inventividade da performance criada pelos dançarinos, performers e designers de som fica perfeitamente dentro dos limites da realização secular da função dramática, como foi muito belamente ilustrado pelo uso do pequeno palco sob uma plataforma de cavalete em Paso Doble. É como se a função dramática, capaz de manifestar-se hoje apenas em raras ocasiões no próprio teatro (isto é, nas práticas artísticas desenvolvidas e exibidas nos espaços institucionais que levam esse nome), tivesse migrado e estivesse se esforçando para encontrar outros espaços onde possa encontrar expressão.

A fim de entender esse fenômeno, volta-se para as lições ensinadas pela antropologia histórica: o espaço específico para o teatro desenvolveu-se a partir de espaços sociais que já eram dramatizados: o salão da casa grande, a praça central da cidade. O teatro estabeleceu-se em lugares ociosos localizados dentro do tecido da cidade (KONIGSON, 2005, p.7). É possível que o espaço da arte sonora constitua hoje uma espécie de equivalente moderno da praça do mercado, um espaço que inspira a circulação de formas e a elaboração de figuras e cenários. O dinamismo deste campo da criação artística, as relações que mantém com a poesia e as novas formas de música, sua localização em uma série de espaços urbanos e meios de comunicação locais (estações de rádio, estúdios, salas de concertos, locais de arte sonora) constituem um vibrante mundo social| ${ }^{23}$, em que as pessoas sintam-se intuitivamente em contato com o mundo onde se vive e este, por sua vez, reflete-se na forma de arte, indiretamente dando-lhe uma definição maior.

É, sem dúvida, a necessidade cada vez mais premente de textos profundos e inspiradores que explica porque, paradoxalmente, tantos espectadores reagem tão fortemente ao som "analfabeto" de Paso Doble, ou, para dar outro exemplo bem conhecido e complementar, ao som sutilmente vocalizado em Paradiso de Romeo Castellucci, criado em Avignon na mesma Église des Célestins em 2008. A improvisação de Alain Mahé, no primeiro caso, a composição de Scott Gibbons, no segundo, não eram substitutos de um texto ausente, não tentaram disfarçar a falta. A composição sonora de Paso Doble parecia estar ouvindo os movimentos expressivos do coreógrafo e escultor, a partir do qual os espectadores podiam mais tarde reconstruir uma narrativa e seus episódios constitutivos, assim como o som de Paradiso formaram

23 "O som eletrônico permite que indivíduos e individualidades participem em múltiplas redes que criam laços e geram uma nova forma de estar-juntos, uma concepção diferente do mundo, aquele que acolhe e incentiva a abertura da imaginação individual e em grupo" (PONDRIAND, 2002). 
uma espécie de eco ao texto de Dante que era referenciado também na instalação e que todos poderiam ir para casa e ler. Esses silêncios falavam mais alto do que muitos textos ineficazes.

\section{Novas memórias coletivas}

Bernard Dort escreveu uma série de artigos ao longo de vários anos sobre a mesma apresentação de Mutter Courage, um dos trabalhos apresentados pelo Berliner Ensemble durante sua passagem por Paris em 1954. O artigo escrito em 1989, no qual ele tira suas próprias conclusões dessa trajetória, é dedicado à questão do tempo (Dort, 1995). Dort começa por recordar seus primeiros comentários. Eles lidam com as sensações imediatas sentidas durante uma representação (um "presente fragmentado" que possui "a realidade de certos pesadelos"); em seguida ele apresenta a interpretação "intelectual" - palavra sua - dada pelos historiadores de Brecht. Para colocá-lo em poucas palavras, o espectador vê e entende o que a personagem Mãe Coragem não vê. Só muito tempo depois é que Bernard Dort descobriu porque esta apresentação havia tocado a ele e a muitos outros tão profundamente: ela recriou a experiência peculiar de tempo, que era a da plateia no período imediatamente posterior à guerra. O que Bernard Dort não diz, mas podemos sem dúvida fazê-lo, é que essa mesma ligação com a realidade era poderosa demais naquele momento para ser expressa em palavras. Dort racionalizou sua experiência de forma brechtiana ao invés de tentar compreender sua emoção imediata. Mas essa emoção foi efetiva, trabalhou, tornou o momento da descoberta do espetáculo inesquecível, suscitou respostas, esforços de pensar e descrever tentativas recorrentes de encontrar o tipo de escrita que poderia lidar com isso, e garantiu que as imagens daquela produção se tornassem um dos ícones do século.

Será que isso significa que os relatos escritos imediatamente (ou quase - oito, quinze, trinta dias) após a representação, nos quais a primeira fase da minha pesquisa foi baseada, são menos relevantes do que aqueles feitos depois que o longo trabalho de memória tivesse ocorrido - como no caso de Bernard Dort? Mas como podemos captar esse testemunho de longo prazo, dado que as emoções iniciais serão intimamente sobrepostas pela experiência de vida posterior? Como essa "ressonância" em longo prazo pode existir no "teatro do presente" (LEHMANN, 2002, p.232), completamente focado na experiência coletiva de estar lá no momento? Este teatro que já não 
é, necessariamente, organizado em torno de um texto escrito parece desencadear em seus espectadores uma intensa necessidade de informações adicionais e produção de vestígios materiais. Um olhar sobre as prateleiras de livros nos foyers dos teatros dá uma ideia do que constitui o novo repertório da memória: os textos dos trabalhos realizados ou os livros a partir do qual a performance deriva, outros textos dos mesmos autores, obras sobre teatro (livros para mesas de centro, textos críticos, ensaios fotográficos, documentos sobre ensaio e gênese do espetáculo) ficam ao lado de DVDs com tiragens especiais e folhetos em anexo. Outros elementos são encontrados na internet, em blogs e outros sites. Algumas vezes alega-se que um abismo separa o período das grandes obras dramáticas, consagradas pela plateia conservadora da época, e o período de eventos de teatro realizados por convidados como co-performers. Ao atribuir aos espectadores de hoje uma função que é ao mesmo tempo discreta e decisiva na vida longa do espetáculo, minha posição é contrária às hipóteses mais rápidas sobre o poder de "presentismo" na vida do novo teatro (HARTOG, 2003).

\section{A título de conclusão}

A função da figura que chamamos de "espectador" é sim fundamental, embora não seja exatamente o que se poderia esperar. Enquanto o momento da apresentação é certamente essencial (parece termos confirmado isto completamente), a relação da plateia com o teatro não pode ser restrita a esse momento. A lição da antropologia histórica é que o teatro na Europa é um dispositivo criado pela sociedade ${ }^{24}$ a fim de elaborar ficções que, por sua vez, ajudam a constituir a sociedade. A operação da função dramática, portanto, depende em grande parte daqueles que comparecem à apresentação, vindo de fora e indo embora depois. Isso nos dá duas tarefas:

- reabilitar, contra as definições midiatizadas do espectador que fazem dele um jogador ou um "interator" integrado ao evento espetacular, a figura do médium mudo (visitante, meditativo, risonho incauto, sonhador inativo), realmente o melhor mediador possível entre as cenas e as múltiplas redes onde tentam se redefinir as formas da vida humana;

- como isso se pratica pelo reconhecimento e pela compressão das imagens, adotar sistematicamente o método da soma e da comparação dos pontos de vista a diferentes distâncias temporais do espetáculo. 


\section{Referências Bibliográficas}

BABLET, Denis. Le lieu, la scénographie et le spectateur. Théâtre/Public, ("Le rôle du spectateur") Paris, V.55, p.18-21, 1984.

BLANC, Jacques. Du musée imaginaire au chantier ou comment placer le spectateur?" In La Position de Spectateur (Aujourd'hui dans la Société et le Théâtre). Du Théâtre, n 5, p.31-35, 1996.

CHANCEREL, Léon. Prospero: Notes, Documents, Etudes, Boutades et Conseils Concernant l'Etude et la Pratique des Arts et Métiers du Théâtre. Du public (premier cahier), Lyon: La Hutte, $n^{\circ} 7,1944$.

DE MARINIS, Marco. Dramaturgy of the spectator. The Drama Review, V.31, N.2, p.100-113, 1987.

DESCOTES, Maurice. Le Public de théâtre et son histoire. Paris: Presses Universitaires de France. 1964.

DESHAYS, Daniel. Pour une Ecriture du Son. Paris: Klincksieck, 2006.

DOAT, Jean. Entrée du Public: la Psychologie Collective et le Théâtre. Paris: Editions de Flore. 1947.

DORT, Bernard. [1989]. "Du passé dans le présent (ou le diamant et le jade)." In Le Jeu du théâtre: le spectateur en dialogue. Paris: P.O.L, 1995, p219-241.

GUÉNOUN, Denis. Le théâtre est-il nécessaire?. Belval: Editions Circé, 1997.

GITELMAN, Lisa. Always Already New: Media, History and the Data of Culture. Cambridge MA: MIT Press, 2006.

GOURDON, Anne-Marie. Théâtre, Public, Perception. Paris: CNRS Editions, 1982.

HARTOG, François. Régimes d'historicité: présentisme et expériences du temps. Paris: Seuil, 2003.

JOURDHEUIL, Jean. Une utopie raisonnable: le spectateur-spectateur. Théâtre/Public, ("Le rôle du spectateur") Paris, V.55, 38-39, 1984.

p.55-63, 2009.

"Chacun pour soi dans les eaux tièdes du management européen." Frictions, V. 15,

KANTOR, Tadeusz. L'endroit lié à la vie In Gaëlle Breton. Théâtres. Paris: Editions du Moniteur, 1989. p.14-15.

KONIGSON, Elie. Le spectateur et son ombre In Odette Aslan (ed). Le Corps en Jeu. Paris: CNRS Editions (Coll. Arts du Spectacle): 1993. P.183-190.

42-49, 1994.

Diviser pour jouer. Les Cahiers de la Comédie-Française, ("Le Spectateur") V 11:

. Espaces construits. In Bénédicte Boisson \& Marie-Madeleine Mervant- Roux (eds).

Théâtre/Public ("Espace privé/Espace public")V. 179, 7-8, 2005.

LATOUR, Bruno. [2005] Changer de société. Refaire de la sociologie. Paris: La Découverte, 2006.

LEFORT, Claude. Essais sur le politique. Paris: Points, 1986.

LEHMANN, Hans-Thies (Philippe-Henri Ledru, trans). [1999]. Le Théâtre postdramatique. Paris: L'Arche, 2002.

MANNONI, Octave. Clefs pour l'imaginaire ou l'Autre Scène. Paris: Seuil, 1969.

MCAULEY, Gay. Space in Performance: Making Meaning in the Theatre. Ann Arbor: University 
of Michigan Press, 1999.

MERVANT-ROUX, Marie-Madeleine. L'Assise du théâtre: pour une étude du spectateur (Coll. Arts du Spectacle). Paris: CNRS Editions 1998.

Du théâtre amateur: Approche historique et anthropologique (Coll. Arts du Spectacle). Paris: CNRS Editions, 2004.

Figurations du spectateur (Coll. Univers théâtral). Paris: L'Harmattan. 2006.

Claude Régy. V. 23, Les Voies de la Création Théâtrale. Paris: CNRS Editions. 2008.

La scène/le son: éloge des limbes. In Sylvie Coellier and Louis Dieuzaide (eds).

Pratiques artistiques transversales et questions politiques. Aix-en-Provence: PUP (Publications de l'Université de Provence), 2010.

De la place des spectateurs dans les mouvements de répertoire In Jeanne Bovet, Yves Jubinville and Brigitte Prost (eds), Le Théâtre de Répertoire: Lieu de Mémoire, Lieu de Création. Rennes: PUR (Presses universitaires de Rennes), 2014.

MNOUCHKINE, Ariane. Entretiens avec Ariane Mnouchkine. In Différent le Théâtre du Soleil. Supplément to Travail Théâtral. Lausanne, p.7-22, 1976.

MOUVEMENT. Mais où vont donc les spectateurs ?, V.32. January/February: 91-102, 2005.

PAVIS, Patrice. Dictionnaire du Théâtre. Paris: Editions Sociales, 1980.

PONDRIAND, Chantal. Electrosons-electrosounds. Parachute, V.107, 2002. (Montreal, JulySeptember). http://www.parachute.ca/public/+100/107.htm\#editofr

RANCIERE, Jacques. Le Spectateur émancipé. Paris: La Fabrique, 2008.

O espectador emancipado. Trad. Ivone C. Benedetti. São Paulo : Ed. WMF Martins Fontes, 2012.

REGNAULT, François. Le Spectateur. Paris: BEBA (Nanterre-Amandiers-Théâtre National de Chaillot), 1986.

RIPOLL, Philippe. Pour un laboratoire du spectateur. In P. Ripoll (ed). La Position de Spectateur (Aujourd'hui dans la Société et le Théâtre), Du Théâtre (hors série n5): p.5-10, 1996.

SAUTER, Willmar. The Theatrical Event: Dynamics of Performance and Perception. Chicago: University of lowa Press, 2000.

SCHAEFFER, Jean-Marie. Adieu à l'Esthétique. Paris: Presses Universitaires de France (Essais du Collège International de Philosophie), 2000.

UBERSFELD, Anne. L’Ecole du spectateur. Paris: Editions Sociales, 1981.

VICTOROFF, David. Le paradoxe du spectateur. Théâtre Populaire, V.12, p.77-82, 1955.

VILAR, Jean. [1946] Définition du public In Armand Delcampe (ed). Le Théâtre, service public. Paris: NRF, Gallimard (Coll. Pratique du théâtre), 1975. p.337-342. 